\title{
A Single Case Study Approach to Teaching: Effects on Learning and Understanding
}

\author{
Tony Jewels \\ Queensland University of Technology, \\ Brisbane, Australia
}

t.jewels@qut.edu.au

\author{
Marilyn Ford \\ Griffith University, \\ Brisbane, Australia
}

m.ford@griffith.edu.au

\begin{abstract}
In the choice of a pedagogy for a new unit on IT project management, an innovative single case study approach was chosen, in the hope of providing a 'virtual environment' in which students could embed themselves. By providing a single, rich, descriptive project environment for students, it was hoped that they would become deeply involved in the case and thus adopt a deeper approach to learning and subsequently a greater understanding of the theoretical constructs covered in the unit. The pedagogy chosen is being evaluated and where necessary revised in what can be described as an action learning approach. Following an initial evaluation of the learning approaches adopted by students, revisions were made to the pedagogy. This paper discusses the findings from two subsequent offerings of the unit.
\end{abstract}

Keywords: IT Project Management, IS/IT Education, Case Study Approach

\section{Introduction}

The need for improvement in the delivery of IT projects has been well documented (Dhillon \& Backhouse, 1996; Hochstrasser, 1993; Lin \& Pervan, 2001; McGunnagle, 1995; Schwalbe, 2002; The Standish Group, 1995, 2001). Many projects are cancelled before completion, many run over budget and over time, and many that are completed have less functionality than expected and are unreliable. There is no doubt that IT project managers have a difficult task when undertaking the management of an IT project. Clearly, there is a need for further research and development of IT project management (ITPM) practices. It is also important that universities educate potential IT project managers so that they can better deal with the complexities of their roles. It is, after all, well-recognised that it is the project manager who is accountable and responsible for what occurs in a project and who must strive to bring the project to a successful conclusion (Cadle \& Yeates, 2001; Nicholas, 2001).

To help educate potential IT project managers, the Faculty of Information Technology of one university believed it was important to deliver their own IT specific project management subject, even though more general units addressing the management of projects were being offered

Material published as part of this journal, either on-line or in print, is copyrighted by Informing Science. Permission to make digital or paper copy of part or all of these works for personal or classroom use is granted without fee provided that the copies are not made or distributed for profit or commercial advantage AND that copies 1) bear this notice in full and 2) give the full citation on the first page. It is permissible to abstract these works so long as credit is given. To copy in all other cases or to republish or to post on a server or to redistribute to lists requires specific permission from the publisher at Publisher@InformingScience.org through other faculties. The ITPM unit, offered as an elective, was carefully structured to provide students with what were believed to be the most appropriate skills and relevant knowledge to take them into the workforce, providing an understanding of factors likely to contribute to project 
success and factors likely to contribute to project failure.

The unit aimed not simply to teach a set of principles and procedures, but to provide students with an appreciation of the complex and multi-disciplinary nature of ITPM, which includes all the administrative, technical, communication and socio-political demands placed on the modern IT project manager. The objectives of the ITPM unit clearly demanded an understanding of ideas and meanings rather than merely learning the techniques used to achieve success in ITPM. An approach to teaching that recognised and encouraged a 'deep approach' rather than the alternative 'surface approach' to learning was therefore considered more desirable. It was believed that the approach of providing a large case study and integrating it into the curriculum could provide students with a 'virtual environment' in which they could become ensconced, allowing them to see, and perhaps experience, the frustrations and elations of working on an IT Project. The case study thus presented a real-world example of an IT project to illustrate the application of the principles and procedures being taught, rather than presenting them in a void.

Initial evaluation of the desired learning outcomes (Jewels \& Bruce, 2003) suggested that the approach did not sufficiently encourage a deep approach to learning. These results appeared to confirm Entwistle's (1988) findings that few students were "able to carry through all the component processes demanded by a fully deep approach which would have resulted in a deep level of understanding", (p28). It was felt, though, that it was worthwhile persisting with the single case study approach to see whether changes could be made to the pedagogy that would encourage more students to take a deep approach. This paper discusses how the approach was modified to better meet the desired learning outcomes and the findings from two subsequent iterations of the unit.

\section{Background}

\section{An Integrated Case Study Approach}

The case study originally used was the 5000 word Dag-Brücken ASRS case study, as it is known, which follows the IT development of an automated storage and retrieval system (ASRS) facility in Asia for a well-known beverage manufacturer. The case describes how the vendor organisation's IT development processes and the environment in which the processes took place may have contributed to the eventual failure of the project and ultimately of the vendor organisation itself. The case covered real events, documented by one of the project team members, and follows the IT development portion of a project over a 20 month period, from the initial requirements stage to the eventual demise of the project and the organisation. The study sets out the contextual details of the environment in which the project took place, the varying expectations of the stakeholders, the requirements of the individual components, the resources available, the development processes, and the cultural and communication factors impinging on the project.

The case study approach is in line with the enhanced equation for learning (L) provided by Hicks (1996): $\mathrm{L}=\mathrm{P}+\mathrm{Q}+\mathrm{ER}$, where ER, "one's own experience reflected on and revised" is added as a component to the more traditional elements of $\mathrm{P}$ (traditional programmed learning) and $\mathrm{Q}$ (questioned learning). According to Hicks (1996, p28), "learning by experience and reflecting on that experience can be most effective in helping students and practitioners acquire professional knowledge and skills". The case study approach, because of its real world nature in which students can become ensconced, may provide experiential learning, thus facilitating the ER component of learning. Moreover, as Mostert \& Sudzina (1996) note, a case method approach to teaching can describe real world problems that would otherwise be too complex to be experienced by students (see also, Glaser \& Strauss, 1967; Lincoln \& Guba, 1985; Patton, 1980). It is, as Barnes, Christensen, \& Hansen (1994) note, a 'second-best' alternative to apprenticeship. 
The approach taken to the design of the unit was intended to encourage a deep learning approach (Biggs, 1987, 1993; Entwistle, 1988; Marton, Hounsell, \& Entwistle, 1997; Marton \& Saljö, 1976; Ramsden, 1992). When taking such an approach, the learner attempts to search for meaning and understanding, relating the current learning to other knowledge and experience, and organising the material into a coherent whole. In contrast, when taking a surface approach, the learner fails to reflect on or integrate the material and is more concerned with memorising or reproducing facts or details. It was felt that a unit on IT Project Management should aim for understanding of ideas and meanings rather than merely the learning of techniques. As Murch (2001) and Mulally (2002) note, IT projects do not normally fail because of a lack of adequate technology. The socalled "hard" skills, such as techniques and methodologies, do not contribute to success as much as the so-called 'soft' skills of good communication and collaboration and connecting with people at all levels of an organisation. A project manager must understand the inter-relationship between the various factors influencing project success, including the all-important 'soft' components. It was hoped that by using a large case study as a focus throughout the unit, a deep learning approach would be encouraged by giving the students the chance to become immersed in the study, allowing them to feel how it would be to be a participant in the project and to come to understood all aspects well. The unit is delivered over a 13 week period and is offered separately to undergraduate and postgraduate students. The unit includes teaching by conventional lectures, guest lecturers, and tutorials. The important topics in IT project management are covered, but with continual reference to the case study, as well as other smaller scenarios. It was first offered in semester 2, 2002, after which an initial study of student learning was undertaken.

\section{The Initial Study}

Jewels \& Bruce (2003) surveyed students who had undertaken the first offering of the unit. They aimed to see whether students had taken a deep or a surface approach to learning and whether the students' results for the unit were influenced by their approach. The relevant tutorial questions took the following form:

This week's tutorial is based around the ITPM unit that you have been studying this semester. Treating the last 13 weeks as a project which you are now reviewing, answer the following evaluation questions using the techniques and processes explained in the PIR lecture.

\section{Describe what this subject has been about.}

\section{What have you learnt about project management?}

\section{In what way did the Dag-Brïcken case study contribute to your understanding of this subject.}

Using the responses to the first two questions, students were classified as having taken a deep, surface, or strategic (mixed) approach to learning. Students were classified as taking a deep approach if they referred to issues of taking responsibility for a project or the role of the project manager in achieving project success. Students were classified as taking a surface approach if they made only specific references to individual processes. Results showed that slightly less than half of the 23 postgraduates and slightly more than a quarter of the 19 undergraduates took a deep approach to learning. There did not appear to be a link between learning approach and students' results for the unit. The third question was used to see how many of the deep learners also took a deep approach to the case, with deep approaches being identified by comments relating to the number or complexity of different factors influencing the project and surface approaches being identified by a concentration on different project management principles. Only 1 of the 5 undergraduate deep learners and only 2 of the 10 postgraduate deep learners took a deep approach to the case. Furthermore, all three of these students received only average grades for the unit. 
The somewhat disappointing results from the initial study prompted the teaching team to take a closer look at how the case study was being integrated into the unit and whether the case was appropriate for its purpose. It was felt that it was worthwhile persisting with the single case study approach to see whether changes could be made that would encourage more students to take a deep approach and, hopefully, be rewarded for doing so. It was subsequently decided to conduct research into desirable features of case studies and also to consider what could be done to encourage students to more deeply embed themselves in the case study.

\section{The Revised Case}

Jewels, Jones \& Ford (2003) reviewed the literature and noted the qualities of cases used for teaching purposes that were likely to contribute most to desired learning outcomes and they evaluated these qualities with those of the actual case used in the first offering of the unit. An original hypothesis was developed to evaluate the suitability of a teaching case for a particular unit:

Case suitability $=\mathrm{fn}\left(\sum\right.$ (generic qualities of the case),

$\sum$ (applicability to individual subject matter to be covered), (applicability to the expected general learning outcome) )

The results indicated that the original case would need to be rewritten if it were to comply with the generic attributes of case studies identified as helping to 'embed' students within a case environment. The case itself was then totally rewritten, expanding it from its original 5000 words to 11000 words. Its suitability as a teaching case was subsequently confirmed by its publication in the Journal of IS Education (Jewels, 2003) which included not only the extended case but also a separate 5000 word teaching notes document.

The research had indicated that important generic qualities of cases included features such as:

- a narrative form and an introductory 'hook' or short attention-grabbing paragraph (Wood \& Anderson, 2001; Cappel \& Schwager, 2002)

- realism (Wright, 1996; Sauer \& Willcocks, 1999; Cappel \& Schwager, 2002)

- a professional problem or problems that need solving (Rees \& Porter, 2002)

The Dag-Brücken case develops a narrative through time, portraying:

- the growing concern of the individual developers as problems are recognised,

- the fragmentation of the development teams,

- the inability of management to cope with important underlying issues, and

- the final fiasco of testing using a totally inadequate test plan.

The multiple viewpoints of the various participants as the project status worsens provides a 'real life' feel to the case, giving students an insight into the reasoning behind decisions made throughout the life of the project. The case certainly has appropriate generic qualities.

The case was also applicable to the individual subject matter to be covered in the unit. The description of the Dag-Brücken management team allowed for consideration of the roles and responsibilities of Project Managers in general. The viewpoints of the various stakeholders allowed for a stakeholder analysis. Significant emphasis was placed on the business reasons for the project, thus allowing an analysis of business cases. The problems inherent in the project manage- 
ment allowed for an analysis of team dynamics, conflict resolution, communication practices, cultural issues and change management. The attempt to develop the system also provides the context for a discussion and analysis of project life cycles, scoping and work breakdown schedules, metrics and estimation, risk management, quality management, and knowledge management. Finally, although the project never reached a 'stabilisation' stage and no Post Implementation Review (PIR) was held, reasons for conducting a PIR could be considered, including the fact that project managers can use PIRs to gain knowledge of what worked and what did not.

The case was also applicable to the expected general learning outcome of the unit. The higher level learning outcome was directed towards a better understanding of how a combination of project management issues, when applied homogeneously, are likely to contribute to project success. The unit aims to teach the fundamental lessons that IT project managers require a range of multidisciplinary skills and that the misapplication of project management knowledge and practices, general management knowledge and practices, or application area knowledge and practices will contribute to project failure. Examples of these three different knowledge areas, considered vital according to the PMI (2000), are provided throughout the case. Moreover, the case makes the roles and responsibilities of the project manager and IT project manager clear and shows how important these roles and responsibilities are. The case also allowed for an examination of the two types of success distinguished by de Wit (1988):

- project management success and

- $\quad$ project success

plus a third type suggested by Cooke-Davies $(2000,2002)$

- organisational success through projects.

It is clear that the revised case satisfied the case suitability function. Of course, it must also be integrated well into the curriculum. To better integrate the case study into the curriculum and to encourage deeper learning, it was also decided to explain to students at the beginning of the unit what higher learning goals were expected. To help do this, the opening lecture explained in diagrammatic form how the unit was structured, how the different components linked together, and why the individual components were delivered separately yet would ultimately contribute to a system perspective.

The unit was offered for a second time in semester 1 of 2003 with the revised case and a clearer integration of the case into the curriculum. A third offering has just been completed. A study was conducted after the second offering to see what effect the changes had on learning approaches and whether the students' results were related to learning approaches. A study was also done during the course of the third offering to see whether students who seemed more 'embedded' in the case gained better results.

\section{Subsequent Offerings with the Revised Case}

\section{The Second Offering}

Once again, the same tutorial questions were asked at the end of the unit and the responses analysed. Responses were obtained from 30 undergraduates and 31 postgraduates, representing approximately $30 \%$ and $60 \%$ of the students enrolled, respectively. Students were categorized as taking different learning approaches using the same criteria as used by Jewels \& Bruce (2003).

It had been hoped that there would be an increase in deep responses from the students given the changes to the case and to the unit. However, the only increase was in the number of students giv- 
ing a mixed response, in which they gave a mixture of deep and surface responding. In the first semester the unit was offered, very few students were identified as giving a mixed response. However, in the second semester of offering, the percentage of students giving mixed responses increased quite dramatically, with the percentage of pure deep and surface responses showing a concomitant decrease, as shown in Table 1.

Table 1. The percentage of deep, surface and mixed responses to learning as a function of year of offering and student status

$\underline{\text { Undergraduates }} \quad \underline{\text { Postgraduates }}$

\begin{tabular}{|l|r|r|r|r|r|r|}
\multicolumn{1}{l}{} & \multicolumn{1}{c}{ Deep } & \multicolumn{1}{c}{ Surface } & \multicolumn{1}{c}{ Mixed } & \multicolumn{1}{c}{ Deep } & \multicolumn{1}{c}{ Surface } & \multicolumn{1}{c}{ Mixed } \\
\hline First offering & 26.3 & 73.7 & 0 & 43.5 & 43.5 & 13.0 \\
\hline Second offering & 10.0 & 53.3 & 36.7 & 29.0 & 35.5 & 35.5 \\
\hline
\end{tabular}

The increase in mixed responding and the decrease in pure deep and surface responding was significant for the undergraduates with $p<.002$ on a Fisher's Exact Test, while for the postgraduates the increase just failed to reach significance, with $p=.058$. While the decrease in purely surface responding is pleasing, it does not seem to have had a great impact on student results. In the first semester of offering, there was on the whole no obvious link between identified learning approach and final grade awarded. In the second semester of offering, there was again no obvious link for the undergraduates. Of the three undergraduates classified as responding with a deep approach, one received the highest grade (a 'High Distinction'), but the other two received a mere 'Pass'. The grades for undergraduates identified as taking a surface approach also ranged from 'High Distinction' to 'Pass' and the grades for those with a mixed response ranged from 'Distinction' to 'Pass'. With the postgraduates there was still a wide range within each learning type, however none of the postgraduates identified as responding with a deep approach received a mere 'Pass'. In contrast, 4 of the surface learners and 4 of the learners with mixed responses received a 'Pass'. Further, the average grade for the postgraduate deep learners was 5.8 (out of the maximum possible of 7), while for the other postgraduates it was 5.0.

The results in Table 1 also show that there is a tendency for more postgraduates than undergraduates to have a deep learning approach. Further, of the 9 postgraduates identified in the second offering as have a deep learning approach, 4 were also identified as taking a deep approach to the case. In contrast, none of the undergraduates identified as taking a deep approach to learning took a deep approach to the case.

It is apparent that the postgraduates are more likely to take a deep approach to their learning, presumably because of their greater maturity and experience. It seems, too, that at best there is only a weak link, and only for the postgraduates, between deep learning and results. Assuming the case is suitable for its purpose and that it is itself integrated sufficiently into the curriculum, there are three main reasons for the lack of a strong relationship between learning approach and results:

- First, it may be that students who do engage in deep learning are not being rewarded appropriately.

- Second, it may be that the way in which the different learning approaches were identified is not sufficiently discriminating.

- Third, it may be that there are important factors, other than whether a deep or surface approach to learning has taken place, that influence students' grades.

It is also possible that all three factors are at play. 
Certainly the marking criteria for the assignments, worth $55 \%$ of the marks of the whole unit, should have rewarded deep learning. However, the assignments were group assignments. It is possible some students were either pulled up or pulled down in marks because of this. Second, it was relatively easy for students, even with surface learning, to gain the $15 \%$ of marks given for tutorial work. This is because there was a chance in the tutorials to do extra work to gain the $15 \%$. Finally, half of the exam and thus $15 \%$ of the unit actually required rote learning. The reason for this is that there were some items for which a commitment to memory was deemed desirable. Moreover, the background of many students had emphasised such learning. Given the assessment procedures, then, it may only ever be possible to find at best a weak link between type of learning and marks.

Let's now consider the identification of the different approaches to learning. It may indeed be that the procedure for identifying different learning types was too weak and subject to extraneous influences. The students were asked to submit their responses to the questions in a tutorial session. Some responses seemed to contain similar phrases which may have come from lectures or handouts, suggesting that at least some students were not reflecting on their learning, but looking at their notes to see what they were supposed to have learned. Some surface learners may have appeared as deep learners because of this factor. Also, some responses were quite brief. It is possible that some students who had taken a deep approach to learning just did not give enough information to help identify them as deep learners. It may be that more valid results would be obtained by giving the questions in an examination situation, where students would need to reflect in order to give their answer and where some nominal marks are given for the response. It is also possible that the categorization based on mention of issues of taking responsibility for a project or the role of the project manager in achieving project success, or specific references to individual processes, was simply too weak to distinguish well between deep and surface learners.

Of course, while factors such as learning approach and maturity or capability may affect understanding and results, other factors would come into play. Student motivation or enthusiasm is probably important, as is the extent to which the material presented aids understanding. These factors would affect all students, even those that are less capable or the students taking a surface approach. The best one can hope for once providing students with an optimal learning situation is that they reach their potential, no matter what their ability, their maturity, or the approach they take.

There is evidence, in fact, that the case did aid understanding and did provide increased enthusiasm and that it was probably very helpful to most students. From examining responses to question 3 after the second offering of the unit, evidence was obtained from the students taking the second offering of the subject that most believed the case had helped their understanding of the subject. All of the 30 undergraduates responded with positive statements about the case and how it contributed to their understanding. Of the 31 postgraduates, 24 made only positive comments about the case, while just 7 made negative comments for various reasons, such as: wanting a case that only had IT components; wanting more, smaller, cases; feeling it was too negative; feeling the English was too difficult to understand; feeling that they did not understand the case; and feeling they were learning more about the case than about project management. Of these 7 students, 1 was identified as a deep learner, 4 as surface learners, and 2 as taking a mixed approach. Of these 7 students, 4 also made positive comments about the case. Overwhelmingly, then, students felt positive about the case and its contribution to their learning. It is very interesting to consider students' positive comments about the case and how it helped their understanding. The following are representative comments from students, categorized according to whether the students had been classified as taking a deep, surface, or mixed approach, given their answers to questions 1 and 2; these responses speak for themselves, expressing recognition that the case aided understanding and in some cases expressing great enthusiasm. 


\section{From postgraduates taking a deep approach to learning}

“... It helps me get a clearer picture ... [of] theory parts in lecture notes and [the] textbook. And it is fun to read ..."

"The Dag-Brucken example was a very helpful case study for understanding the managerial skills that were lacking in such a huge IT project ...[it] makes it an exciting unit..."

"The Dag-Bruken case study was vitally important to my understanding of this subject. It created a common reference point for all class members ..."

“...I think the case is so rich in nuance that inevitably it must form the core of the learning...”

\section{From postgraduates taking a mixed approach to learning}

“...this case study contributed a lot in the understanding of this subject. I understood the basic theory which was taught in the lecture well because this was all practically visible in the case study..."

“...I have learnt immensely from the case study for example things not to do and things to do and why it's important”

\section{From postgraduates taking a surface approach to learning}

"[The] Dag-Brucken case study gave a good insight about a real time project. At some stage of the case study I could feel as if the project was actually happening and we were the project managers in it."

"From the problems found in the Dag Bruken case study, I realized ... the importance of the issues covered in the lectures. I have more understanding [of] how to implement those soft and technical skills ..."

“... It assists me in relating theories in lectures to the real-world scenarios and helps me remember the importance of the theories"

"The Dag-Brucken case study contributed significantly to understanding this subject. It assisted in highlighting the importance of the components of good project management..."

\section{From undergraduates taking a deep approach to learning}

“...DB helps me understand the available techniques such as risk assessment and quality control while applying them to this 'bottom line'”

"Dag-Brucken case study has contributed [to my] understanding ...the client's needs are very important to the [success] of the project..."

\section{From undergraduates taking a mixed approach to learning}

“...I think it is an excellent idea to look at a very bad example and try and pull out where to change things...” 
"This case study...made it easier and more obvious to think of ways that the project should be performed...It was interesting to see how many things you can ...do wrong..."

"The case played an important role as it allowed me to understand the theory by applying and comparing it to Dag Brucken. I could understand exactly what went wrong, and was taught the skills to do it better..."

"The case study...improved my understanding that every single factor must be controlled in order to maximize the chances of project success"

\section{From undergraduates taking a surface approach to learning}

"[It] will never be forgotten for me as a student, as the real [consequences] of neglecting the IT project management rules were demonstrated perfectly using the DB case study"

“...Because it was a real life case study I found it easier to put in practice the concepts being taught in lectures"

" $D B$ is a good bad example...we can truly appreciate and see the importance of the right project management techniques..."

“...Surely it reduced the processing in this unit for all the students..."

"The case helped to expand the theory. For some students I spoke to, who did not have industry experience, it helped explain the theory and show them why the theory is important and how to apply it (or not apply it)..."

"With a real life case study, I can actually relate better to why project management is important..."

It is clear that regardless of student status and learning approach, overwhelmingly students felt that the case helped their understanding of the unit. A great deal of enthusiasm also comes through in the responses. It may indeed be that students of varying capabilities and maturity levels and taking different learning approaches were helped by the case study. Thus, even if the case study did not encourage a deep approach in all students, it seems it did, to a great extent, instill enthusiasm and lead to increased understanding. It may indeed have helped students of different ability to reach their potential.

\section{The Third Offering}

The results from the second offering indicate that most students did benefit from the integrated case study approach, with students saying, overwhelmingly, that the case aided understanding and with many students seeming very enthusiastic. However, it seemed that there was no link between identified learning approach and undergraduate results and, at best, a very weak link between learning approach and postgraduate results. During the third offering of the unit a different means of identifying students taking different learning approaches became apparent.

The degree to which students were willing, or able, to 'embed' themselves in the Dag-Brücken case could be considered one indication of the extent of deep or surface learning. Presumably those students who do 'embed' themselves in the case study are not taking a surface approach, but are instead involving themselves more deeply, trying to make connections and seeking meaning and understanding of the different facets of the case. However, questions $1-3$ used after the first and second offerings of the unit did not assess the degree of 'embedding' of oneself in the case study. It was noticed, though, in the just completed, third, offering of the unit that students 
varied markedly in the extent to which they did 'embed' themselves. Both assignments required consideration of the case study. Consider the following, taken from the Assignment 1 task:

"The managing director (MD) has asked you to provide him with a report explaining what a knowledge worker is and how Dag-Brücken might have to adopt ... project management techniques to more closely match any requirements of this type of worker."

To do this assignment well, students would need to research the literature on knowledge workers and project management techniques for such workers and they would need to evaluate the current project management techniques of Dag-Brücken in this light, determining how new techniques would be more suitable. Notice that a student could do well without thinking about the fact that they are meant to be writing to the managing director of Dag-Brücken. It is possible, though, to gain some idea of whether students were 'embedded' in the case by seeing whether they did purposely write for the managing director (MD). Students who did not purposely write for the MD were clearly not 'embedded' in the case. Those who did write for the MD were at least somewhat 'embedded', taking the focus on the case seriously and attempting to work somewhat within a coherent framework. On reading the assignments it was clear that some students neglected to consider whom they were writing for. Consider the following statement from one postgraduate assignment:

“... Knowledge workers tend to work more proficiently when their work is recognized. In [the] case of Dag Brucken there was apprehension as the managing director was considered to be a despot ..."

It is unlikely that anyone writing for the MD would make this statement. The question thus arises: Did students who felt that they did write their report for the MD, and who were thus more 'embedded' in the case, receive better marks? In one of the lectures before the assignments were returned, the postgraduate students were asked to complete a survey. One question asked whether, when writing the report, they had kept in mind the fact they were writing for the MD and had written the report as though it was for the MD. It was found that there was a relationship between whether they felt they had done this and their marks, as shown in Table 2.

Table 2. Student marks as a function of whether they believed they had written their report for the MD.

\begin{tabular}{|l|c|c|}
\hline & $\frac{\text { Marks from 50-69 }}{}$ & Marks of 70 and above \\
\hline Wrote with MD in mind & 3 & 9 \\
\hline Did not write with MD in mind & 15 & 5 \\
\hline
\end{tabular}

Students who admitted that they had not kept in mind that they were writing for the MD were less likely to receive good marks. The results were significant, with $p<.008$ on a Fisher's Exact Test.

The students were also asked whether they thought a reader would be thoroughly convinced the report was written for the MD. Again, it was found that there was a relationship with results, as shown in Table 3.

None of the students who received lower marks believed that a reader would be convinced the report was written for the MD, while half of the students with higher marks believed a reader would be convinced. Again the results were significant, with $p=.001$ on a Fisher's Exact Test. 
Table 3. Student marks as a function of whether they believed a reader would be convinced the report was for the MD.

\begin{tabular}{|c|c|c|}
\hline & Marks from 50-69 & Marks of 70 and above \\
\hline The reader would be convinced & 0 & 7 \\
\hline The reader would not be convinced & 18 & 7 \\
\hline
\end{tabular}

It seems, then, that the students who 'embedded' themselves in the case were more likely to receive higher marks. Given that a student could do well without purposely writing for the managing director of Dag-Brücken, the results cannot be due to gaining marks for making it clear whom the document was written for. It may be that the 'embedding' helped students achieve. Of course, it is possible, too, that it is the more capable students who are the very ones who can 'embed' themselves in a case. The results do show, though, that some students are 'embedding' themselves in the case and receiving good marks. Given the relationship between results and the way students perceived whether and how effectively they had written the assignments specifically for the MD, it may be that this kind of survey, which attempts to see how 'embedded' a student is in a case study, is more appropriate for accessing whether deep or surface learning has taken place rather than questions about what they have learnt. Unfortunately, as the questionnaire about the assignment was done somewhat on the spur of the moment during the third offering of the unit, the undergraduates were not surveyed.

\section{Summary}

The integrated case study approach was intended to provide students with a 'virtual environment' in which they could become ensconced, allowing them to see, and perhaps to some extent experience, the emotions of working on an IT project. Such an approach was intended to provide an experiential component to learning (Hicks, 1996) and to encourage a deep learning approach (Biggs, 1987, 1993; Entwistle, 1988; Marton, Hounsell, \& Entwistle, 1997; Marton \& Saljö, 1976; Ramsden, 1992) and hence a better understanding of project management principles and issues. While the results of an initial study were disappointing, results from the next two iterations were more promising.

The classification of students into deep and surface learners on the basis of questions about what they had learned was not very fruitful. Using this approach, there seemed to be no increase in the number of students taking a deep approach in the second iteration of the unit and only a very weak link between approach and results for the postgraduate students and no link for the undergraduates. However, the comments obtained after the second iteration of the unit showed that there was a great deal of enthusiasm about the use of the case and that students felt, overwhelmingly, that the case helped their understanding. Moreover, in the third iteration for the postgraduate unit, it was shown that using questions to determine how 'embedded' students were in the case in order to discriminate between deep and surface learners yields a strong relationship between results and learning approach. It seems, then, that the integrated case study approach did help students' understanding, though it did not necessarily help all students to take a deep level approach to learning. It seems, too, that students who were more 'embedded' in the case achieved better results. 


\section{Further Directions for Research}

Several questions arise that require further research:

1. Is there a strong relationship between how 'embedded' an undergraduate is in a case and their results?

2. Can better, more general, methods be found for determining how 'embedded' in a case a student is?

3. What makes some students become more 'embedded' in a case than others?

4. How can more students be encouraged to become 'embedded' in a case?

5. How can students be better rewarded for taking a deep learning approach?

The integrated case study approach does seem to be an aid to helping students reach their potential, but answers to the above questions may help more students achieve even closer to the potential they have.

\section{References}

Barnes, L. B. Christensen, C. R. \& Hansen, A. J. (1994). Teaching and the case method: Text cases and readings $\left(3^{\text {rd }}\right.$ ed.). Harvard Business School Press.

Biggs, J. B. (1987). Student approaches to learning and studying. Hawthorne, Victoria: Australian Council for Educational Research.

Biggs, J. B. (1993). What do inventories of students' learning processes really measure? A theoretical review and clarification. British Journal of Educational Psychology, 63, 3-19.

Cadle, J. \& Yeates, D. (2001). Project management for information systems $\left(3^{\text {rd }}\right.$ ed.). Malaysia: Pearson Education.

Cappel, J. \& Schwager, P. (2002) Writing IS teaching cases: Guidelines for JISE submission. Journal of Information Systems Education, 13 (4).

Cooke-Davies, T. (2000). Towards improved project management practice. Uncovering the evidence for effective practices through empirical research. PhD Thesis, Leeds Metropolitan University, Leeds.

Cooke-Davies, T. (2002). The "real" success factors on projects. International Journal of Project Management, 20 (3), 185-180.

de Wit, A. (1988). Measurement of project success. International Journal of Project Management, 6 (3), 164-170.

Dhillon, G. \& Backhouse, J. (1996). Risks in the use of information technology within organizations. International Journal of Information Management, 16 (1), 65-74.

Entwistle, N. (1988). Motivational factors in students' approaches to learning. In R. R. Schmeck (Ed.), Learning Strategies and Learning Styles. USA: Plenum Press.

Glaser, B. G. \& Strauss, A. L. (1967). Teaching and the case method. Boston, MA: Harvard Business School.

Hicks, R. E. (1996). Experiential learning in a postgraduate project management programme, Education + Training, 38 (3), 28-38.

Hochstrasser, B. (1993). Quality engineering: A new framework applied to justifying and prioritising IT investment. European Journal of Information Systems, 2 (3), 211-223.

Jewels, T. (2003). The Dag-Brücken ASRS case study. Journal of Information Systems Education: Special Issue on IS Teaching Cases, 14 (3), 247-257. 
Jewels, T., \& Bruce, C. (2003, June 24-27). Using a case method approach in an IT project management curriculum: A long look over the shoulder of a practitioner at work. Paper presented at the Informing Science + IT Education Conference, Pori, Finland.

Jewels, T., Jones, W., \& Ford, M. (2003, 26-28th November). A study of cases: Evaluating requirements. Paper presented at the 14th Australasian Conference on Information Systems, Perth, Western Australia.

Lin, C. \& Pervan, G. (2001). IS/IT investment evaluation and benefits realisation issues in a government organization. Proceedings of the Twelfth Australasian Conference on Information Systems, Coffs Harbour, Australia.

Lincoln, Y. L. \& Guba, E. G. (1985). Naturalistic inquiry. Beverly Hills, CA: Sage.

Marton, F., Hounsell, D. \& Entwistle, N. J. (Eds.). (1997). The experience of learning: Implications for teaching and studying in higher education ( $2^{\text {nd }}$ ed.). Edinburgh: Scottish Academic Press.

Marton, F. \& Saljö, R. (1976). On qualititative differences in learning: 1.outcome and process, British Journal of Educational Psychology, 46, 4-11.

McGunnagle, G. P. (1995). Corporate banking: Making technology more effective. Bank Management, 71 (6), 22-25.

Mostert, M. P. \& Sudzina, M. R. (1996). Undergraduate case method teaching: Pedagogical assumptions vs the real world. Proceedings of the Annual Meeting of the Association of Teacher Educators, St Louis Missouri, February, 1996.

Mulally, M. E. (2002). Developing project managers into organizational leaders. Gantthead.com. Retrieved 22nd November, 2003 from http://www.gantthead.com/Gantthead/articles/articlesPrint/1,1685,115890,00.html

Murch, R. (2001). Project management Best practices for IT professionals. USA: Prentice Hall.

Nicholas, J. M. (2001). Project management for business and technology $\left(2^{\text {nd }}\right.$ ed.). USA: Prentice Hall.

Patton, M. Q. (1980). Qualitative evaluation methods. Newbury Park: Sage Publications.

PMI. (2000). A guide to the project management body of knowledge. White Plains: Project Management Institute.

Ramsden, P. (1992). Learning to teach in higher education. Routledge: Chatham.

Rees, W. D. \& Porter, C. (2002) The use of case studies in management training and development Part 1, Industrial and Commercial Training, 34 (1), 5-8.

Sauer, C. \& Willcocks, L. (1999) Teaching cases for information systems. Journal of Information Technology, Special Issue (14), 213-216.

Schwalbe, K. (2002). Information technology project management ( $2^{\text {nd }}$ ed.). Canada: Course Technology.

The Standish Group (1995). The Standish Group Report. Retrieved $22^{\text {nd }}$ November, 2003 from http://www.scs.carleton.ca/ beau/PM/Standish-Report.html

The Standish Group (2001). Collaboration: Development \& Management: Collaborating on Project Success. Retrieved $8^{\text {th }}$ December, 2003 from http://www.softwaremag.com/archive/2001feb/CollaborativeMgt.html

Wood, A. T. \& Anderson, C. H. (2001) The case study method: Critical thinking enhanced by effective teacher questioning skills. Proceedings of International Conference of the World Association for Case Method Research \& Application, Lund, Sweden, June 17-20.

Wright, P. (1996). Simulating reality: The role of the case incident in higher education. Education + Training, 38 (6), 20-24. 


\section{Biographies}

Tony Jewels is currently a lecturer within the School of Information Systems at Queensland University of Technology. An IT professional for over 30 years, he has worked in a variety of roles on leading edge IT projects throughout the world. He coordinates the undergraduate and postgraduate IT Project Management units at QUT and is currently researching motivations for knowledge sharing in IT project teams.

Marilyn Ford is a senior lecturer in Computing and Information Technology at Griffith University. She currently teaches User Interface Design, Writing Skills, and Reasoning, and tutors in the IT Project Management unit used as the basis for the research presented here. She has had extensive research experience in reasoning and language processing having held previous positions at both Massachusetts Institute of Technology and Stanford University. 